\title{
Analysis on the groundwater salt dynamic in a monitoring area in Hetao Irrigation District of Inner Mongolia
}

\author{
Yuan Chengfu' ${ }^{1,2}$ \\ 1 College of Hydraulic Science and Engineering, Yangzhou University, Yangzhou 225009, Jiangsu, China \\ 2 Jiangxi Water Resources Institute, Nanchang 330013, Jiangxi, China
}

\begin{abstract}
In order to explore the rule of groundwater salt dynamic in Hetao Irrigation District, a typical monitoring area was selected as the research area in Yongji Irrigation Area of Hetao Irrigation District. The groundwater level and groundwater salinity were analyzed during the year and inter-annual variation in 2008-2013. The groundwater level showed an obvious seasonal change trend during the year variation. The groundwater level was at the peak value after spring irrigation and autumn irrigation. The groundwater level was at the low value before melting and autumn irrigation. The groundwater level had an obvious periodicity during the inter-annual variation. The groundwater level could keep a relatively stable for many years. The groundwater salinity showed an obvious seasonal change trend during the year variation. The groundwater salinity was greatly affected by irrigation and had a decreased trend after irrigation. The groundwater salinity had an obvious periodicity during the inter-annual variation and could keep a relatively stable for many years in cultivated land. The groundwater salinity had an increased trend during the interannual variation in wasteland. The wasteland was the drainage area for cultivated land. The wasteland had an obvious role in adjusting salt dynamic balance in Hetao Irrigation District.
\end{abstract}

\section{Introduction}

For arid and semi-arid areas, groundwater is a unique water resource, which plays an important role in maintaining social and economic development and agricultural production. However, excessive irrigation in agricultural production will cause the elevation of groundwater level. In addition, due to the arid climate conditions, soil moisture and groundwater evaporation are strong, which will cause the gradual accumulation of soil salt and the increase of groundwater salinity, which will cause the harm of soil secondary salinization and seriously threaten the agricultural production in arid and semi-arid areas. High groundwater level is the main cause of soil secondary salinization in arid and semi-arid areas, and controlling groundwater level is also the key to prevent soil secondary salinization. In order to solve the problem of soil secondary salinization in arid and semi-arid areas, researchers at home and abroad have carried out a lot of researches on the dynamic law of groundwater salt and the regulation of groundwater level ${ }^{[1,2]}$. The Hetao Irrigation Area in Inner Mongolia, located in the upper reaches of the Yellow River Basin, is a typical saline alkali irrigation area because of its dry climate, less rainfall, strong evaporation, shallow groundwater level and high salt content in soil parent material ${ }^{[3]}$. In recent years, with the aggravation of water resources shortage in the Yellow River Basin, the allowable water diversion volume of Hetao irrigation area has decreased from 5.2 billion $\mathrm{m}^{3}$ to about 4 billion $\mathrm{m}^{3[4]}$. The continuous reduction of water diversion from the Yellow River will lead to the change of groundwater salt dynamics in the irrigation area, and the original water salt balance will be broken, but the new water salt balance is still unclear. At present, the research on groundwater salt dynamics in Hetao irrigation area mainly focuses on the spatiotemporal variation of groundwater depth, the spatiotemporal variation characteristics of groundwater salinity, the impact of groundwater level change on groundwater environment after water-saving reconstruction, and the impact of groundwater level change on soil water, salt and crop growth. However, the dynamic changes of groundwater salt in different landscape units of Hetao irrigation area are less studied. In this study, a typical monitoring area was selected in Hetao Irrigation District of Inner Mongolia. Based on the analysis of groundwater level and mineralization data of typical monitoring area from 2008 to 2013, the annual dynamic change law of groundwater level and mineralization degree of different landscape units in typical monitoring area was studied. The research results can provide scientific basis for water resources management and effective utilization in Hetao irrigation area.

\section{Materials and Methods}

Hetao irrigation area is the largest large-scale gravity irrigation area in China and even in Asia. It is one of the

\footnotetext{
* Corresponding author: cfyuan1989@163.com
} 
three largest irrigation areas in China, and also an important national commodity grain production base. Agriculture is an important pillar industry of the economy of the irrigation area. Hetao irrigation area is $250 \mathrm{~km}$ long from east to west and $50 \mathrm{~km}$ wide from south to north. The total land area of Hetao irrigation area is 17.94 million $\mathrm{mu}$, the control area of irrigation area is 16 million mu, the designed irrigation area is 11 million $\mathrm{mu}$, and the existing irrigation area is 8.61 million mu. Hetao irrigation area is composed of five irrigation areas: Ulanbuhe irrigation area, Jiefangzha irrigation area, Yongji irrigation area, Yichang irrigation area and Wulat irrigation area. A total of 220 groundwater observation wells (Figure 1) have been arranged by the local water management department in 5 irrigation areas to monitor the groundwater level and groundwater mineralization degree in Hetao irrigation area for a long time.

A typical monitoring area is selected in Hetao irrigation area, which is located in the southwest of Yongji irrigation area in the middle reaches of Hetao irrigation area, which is the control area of Heji main canal, with the control area of 166.68 In the typical monitoring area, there are 85\#, 124\#, 128\#, 134\# and 136 \# underground water monitoring wells (Figure 2). $85 \#$ are arranged in villages, $124 \#$ and $134 \#$ are arranged in wasteland, 128\# and 136\# are arranged in cultivated land. Monitoring wells basically reflect the composition of different landscape units in the study area. The groundwater level data of 5 groundwater monitoring wells from 2008 to 2013 were collected. The groundwater level was observed by the staff of Yongji irrigation area every 5 days. The groundwater depth was measured by the steel ruler water level gauge, and the groundwater level elevation was obtained by subtracting the groundwater depth from the wellhead elevation. The groundwater conductivity $\mathrm{EC}(\mathrm{mS} / \mathrm{cm})$ of the monitoring well is measured by portable conductivity meter, and then converted into groundwater mineralization degree $\mathrm{T}(\mathrm{g} / \mathrm{L})$ according to the relevant formula $(\mathrm{T}=0.69 \mathrm{EC})^{[5]}$. The groundwater salinity is measured once every two months. Due to the incompleteness of groundwater salinity data, only $128 \#$ and $134 \#$ groundwater salinity data during 2008-2013 are collected.

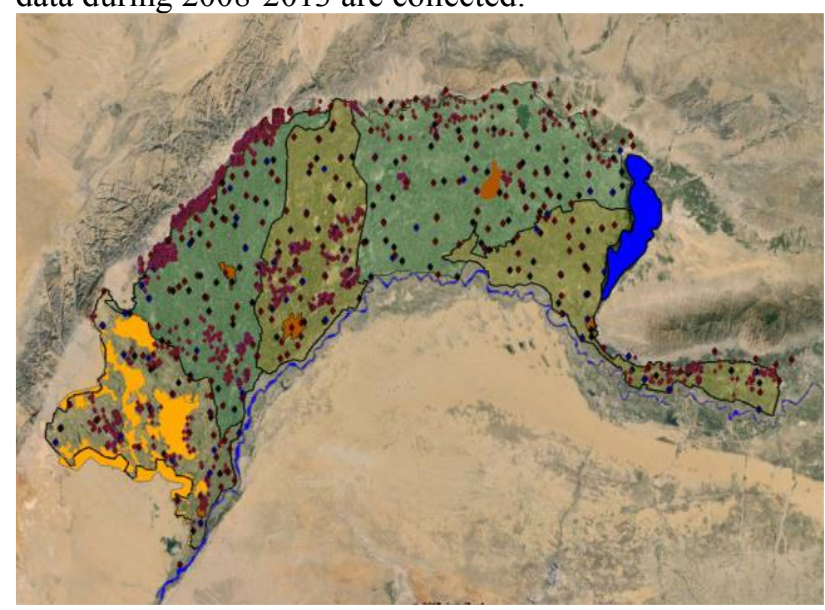

Fig. 1. Distribution of groundwater monitoring wells in Hetao Irrigation Area

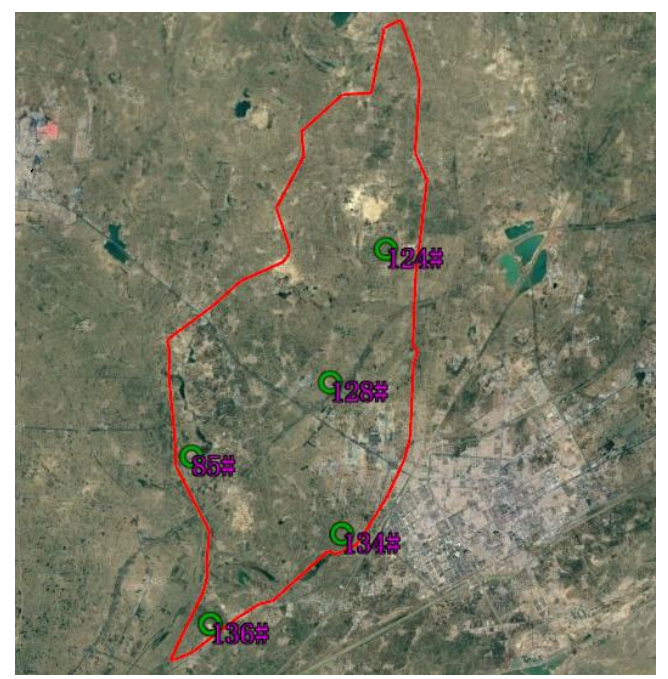

Fig. 2. Distribution of groundwater monitoring wells in typical monitoring area

\section{Results and Analysis}

\subsection{Annual dynamic analysis of groundwater level}

The annual dynamic change of groundwater level of each monitoring well in 2013 is shown in Figure 3. It can be seen from Figure 3 that the variation law of groundwater level in each monitoring well is basically similar. From January to early March, the groundwater level of each monitoring well shows a downward trend. This is the freezing period of the study area. The external temperature is low, and the soil is gradually frozen from the surface layer to the lower layer. The thickness of the frozen soil layer is $1.0-1.5 \mathrm{~m}$, so the groundwater level gradually drops. From March to the beginning of May, the groundwater level of each monitoring well is gradually rising, and this is the thawing period of the study area. This is mainly because the external temperature gradually rises in March and the soil begins to melt, and the soil completely melts in late April, and the groundwater level gradually rises. The period from May to the end of September is the growing period of crops in the study area. At this time, the change of groundwater level is more obvious. The spring irrigation period of the study area is the beginning of May. The first irrigation is carried out in the study area, and the amount of farmland irrigation reaches $180 \mathrm{~mm}$ in the middle and late May, the groundwater level of each monitoring well rises to a relatively high value. The crops in the study area are generally irrigated 3-4 times in the growing period. Before and after the crop irrigation, the groundwater level of each monitoring well changes obviously. The last irrigation of crops in the study area is in the first ten days of August which is the lowest value of a year is in the early stage of autumn irrigation. The autumn irrigation period of the study area is from October to early November, which lasts about 40 days. Autumn irrigation is the period with the largest amount of irrigation in a year, and the amount of autumn irrigation is about $200 \mathrm{~mm}$. The main function of autumn 
irrigation is to leach the soil salt of cultivated land in the study area, and provide favorable conditions for crop growth in the next year. The freezing period is from mid November to march of the next year, and the groundwater level of each monitoring well gradually drops. The groundwater level of the monitoring wells in different landscape units in the study area is slightly different. $85 \#$ is arranged in the village. Because the village is far away from the cultivated land, the impact on the village groundwater level is slow and relatively weak after the cultivated land is irrigated. Compared with the groundwater level of other monitoring wells, the change of $85 \#$ groundwater level is not very significant. Wasteland is adjacent to cultivated land, and the groundwater level of wasteland is obviously affected by farmland irrigation. The variation of groundwater level in wasteland 124\# and 134\#, is basically similar to that of cultivated land $128 \#$ and $136 \#$.

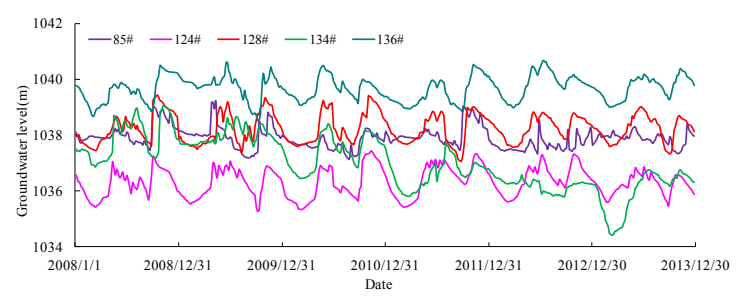

Fig. 3. Annual dynamic change of groundwater level

\subsection{Inter-annual dynamic analysis of groundwater level}

Figure 4 shows the inter-annual variation of groundwater level of each monitoring well in 6 years. It can be seen from Figure 4 that the groundwater level of the rest of the groundwater monitoring wells changes little from year to year except 134\# of wasteland. Although the groundwater level of each monitoring well changes greatly in different months for many years, it can basically maintain a stable change state. According to the linear fitting of the groundwater level of each monitoring well, it can be seen that the groundwater level of each monitoring well at the end of 2013 and the beginning of 2008 is basically the same, the average groundwater level of each year is basically unchanged, and the groundwater resources in the study area can basically maintain an equilibrium state. The groundwater level showed a downward trend during the six years, which may be related to the water-saving transformation of farmland in the area where 134\# was located, or the area of cultivated land was reduced and the water diversion volume was reduced, which led to the gradual decline of groundwater level.

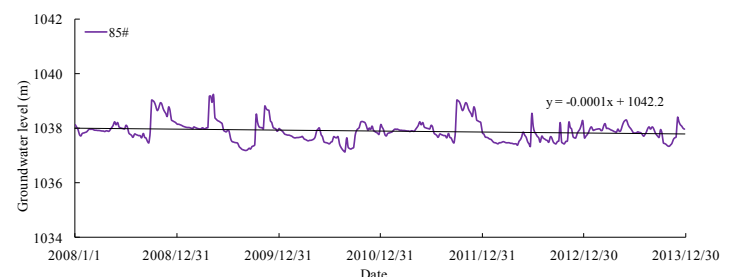

(a) $85 \#$

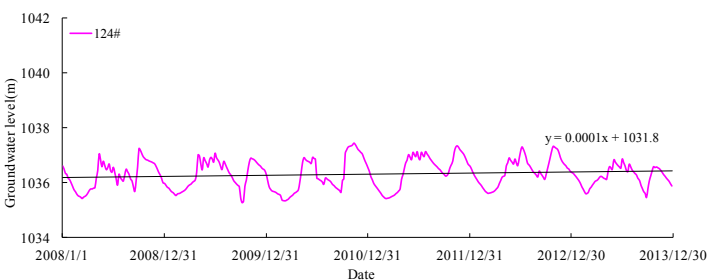

(b) $124 \#$

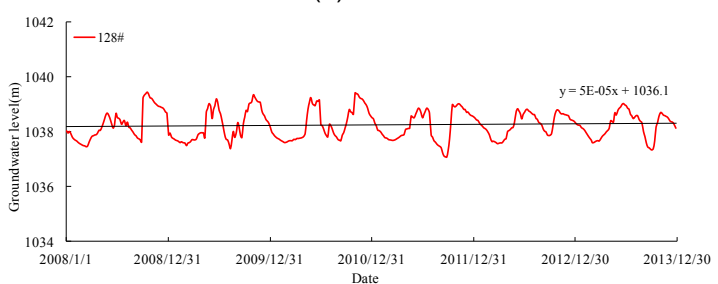

(c) $128 \#$

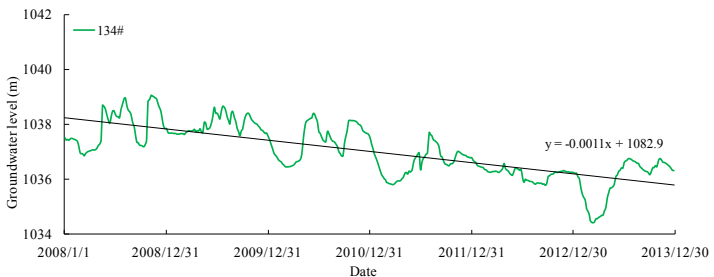

(d) $134 \#$

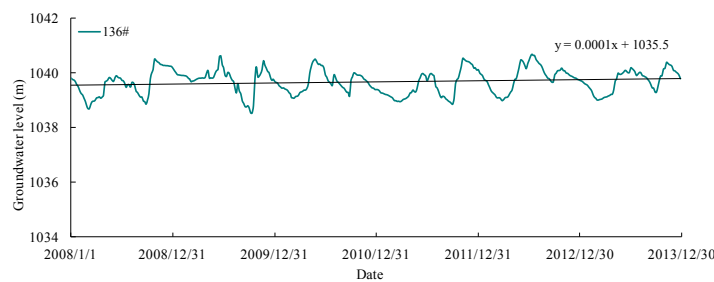

(e) $136 \#$

Fig. 4. Inter-annual variation of groundwater level

\subsection{Annual dynamic analysis of groundwater salinity}

The annual dynamic changes of groundwater salinity in $128 \#$ and $134 \#$ in 2013 are shown in Figure 5. It can be seen from Figure 5 that the groundwater salinity is monitored once every two months, and the groundwater salinity data is relatively small, but the groundwater mineralization degree generally presents a certain rule, that is, the groundwater mineralization degree presents a downward trend within the year, which is mainly affected by irrigation in different periods. The groundwater mineralization degree of cultivated land and wasteland can be affected after farmland crops are irrigated. During the freezing period from January to March, the salinity of groundwater increases, which mainly occurs in the freezing period when the soil freezes from the surface layer to the lower layer, and the soil evaporation gradually weakens, and the groundwater salinity increases. In the middle and late March, the soil begins to melt, and the groundwater level gradually rises. Under the action of soil evaporation, groundwater migrates into the soil, and the soil salinity increases gradually the mineralization degree shows a decreasing trend. April to August is the growing period of crops in the study area, and the mineralization degree of groundwater changes significantly before and after 
irrigation in the irrigation season. There is no irrigation in September, the groundwater level gradually decreases, and the groundwater salinity has a gradual increase trend; October November is the autumn irrigation period in the study area, because of the large amount of irrigation in autumn irrigation period, the groundwater level rises rapidly the salinity of water decreased gradually. The mineralization degree of groundwater in different landscape units is slightly different. The mineralization degree of groundwater in cultivated land $128 \#$ is lower, the average mineralization degree of groundwater is 0.94 $\mathrm{g} / \mathrm{L}$, and the change of groundwater mineralization degree of cultivated land is relatively small. The mineralization degree of groundwater in wasteland 134\# is higher, and the average mineralization degree of groundwater is $4.54 \mathrm{~g} / \mathrm{L}$.

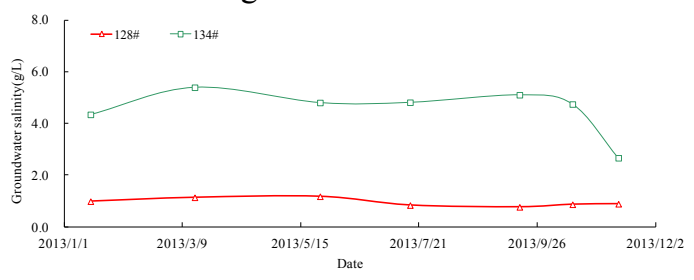

Fig. 5. Annual variation of groundwater salinity

\subsection{Inter-annual dynamic analysis of groundwater salinity}

Figure 6 shows the inter-annual variation of groundwater mineralization degree in $128 \#$ and 134\# monitoring wells in 6 years. The results show that the groundwater mineralization degree is mainly affected by the annual variation of groundwater salinity in cultivated land the salinity of groundwater in cultivated land also flows to wasteland along with groundwater flow, resulting in the increase of groundwater mineralization in wasteland. The average mineralization degree of groundwater in cultivated land was $0.85 \mathrm{~g} / \mathrm{L}$ during 6 years, which indicated that $128 \#$ groundwater was fresh water, and the groundwater of cultivated land remained fresh water after long-term irrigation from Yellow River. The average mineralization degree of groundwater in wasteland was $4.30 \mathrm{~g} / \mathrm{L}$ in 6 years with the continuous irrigation of the Yellow River, the groundwater from the cultivated land flows to the wasteland, resulting in the groundwater salinity increasing gradually. This also shows that the salt leaching from cultivated land migrates to the wasteland, and the wasteland becomes the drainage and salt drainage area of cultivated land, and the wasteland plays a role in maintaining the dynamic balance of salt content in Hetao irrigation area.

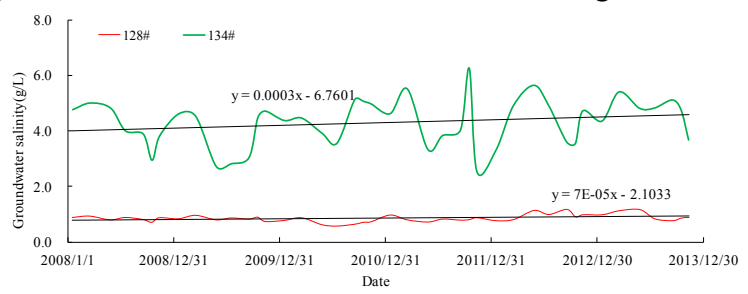

Fig. 6. Inter-annual variation of groundwater salinity

\section{Conclusions}

The groundwater level was influenced by irrigation, evaporation, crop water consumption, freeze-thaw and other factors, in Hetao irrigation area changes seasonally within the year. The dynamic change of groundwater level in the year presents the phenomenon of "two peaks and two valleys", that is, the groundwater level is at the peak after spring irrigation and autumn irrigation, and the groundwater level is at the low value before the fusion and autumn irrigation. The groundwater level changes periodically from year to year. The groundwater level can be kept stable for many years, and the groundwater resources in the study area can basically maintain an equilibrium state. The salinity of groundwater in Hetao irrigation area changes seasonally in a year. The salinity of groundwater is greatly affected by irrigation. After irrigation, the salinity of groundwater decreases gradually. The annual variation of groundwater salinity of cultivated land is relatively stable, and the salinity of irrigated farmland moves to wasteland with groundwater. The annual salinity of groundwater in wasteland has an increasing trend. Wasteland is the drainage and salt drainage area of cultivated land, and wasteland has the function of maintaining salt dynamic balance in Hetao irrigation area.

\section{Acknowledgements}

This research was supported by Postgraduate Research \&Practice Innovation Program of Jiangsu Province

(XKYCX18_065) and the Key Popularized Programs of Water Conservancy Bureau of Jiangxi Provice Science and Technology Achievement(202022TGKT07).

\section{References}

1. Yong X, Xiao M G, Shi Y Y. (2016) Geostatistical interpolation model selection based on ArcGIS and spatio-temporal variability analysis of groundwater level in piedmont plains, northwest China. Springer Plus, 5(1): 1-15.

2. Lu Y, Wang L, Zhang H L. (2017) Study on law of groundwater-salt transportation in Pingluo WellCanal combined irrigation district in Ningxia. Water Res. Hydro. Eng. 48(3): 165-170.

3. Huang Q Z, Xu X, Lü L J. (2018) Soil salinity distribution based on remote sensing and its effect on crop growth in Hetao Irrigation District. Transactions of the CSAE, 34(1): 102-109.

4. Li L, Li M Y, Wang S F. (2015) Analysis of salt accumulation in wasteland of Jiefangzha irrigation field in Hetao Irrigation District. J. Drain. Irri. Mach.Eng. 33(5): 434 -441.

5. Ren D Y, Xu X, Hao Y Y. (2016) Modeling and assessing field irrigation water use in a canal system of Hetao, upper Yellow River basin: Application to maize, sunflower and watermelon. J. Hydro., 532: 122-139. 